\title{
Re-Finding PL.AC.E. for Walking: Assessment of Key-Elements Using Questionnaire
}

\author{
Fritz Akhmad Nuzir ${ }^{1,2}$, Bart Dewancker ${ }^{3}$ \\ ${ }^{1}$ Graduate School of Environmental Engineering, the University of Kitakyushu, Kitakyushu, Japan \\ ${ }^{2}$ Architecture Study Program, Faculty of Engineering, Bandar Lampung University, Bandar Lampung, Indonesia \\ ${ }^{3}$ Department of Architecture, Faculty of Engineering, the University of Kitakyushu, Kitakyushu, Japan \\ Email: fritz.ahmad@gmail.com,bart@kitakyu-u.ac.jp
}

Received 15 September 2015; accepted 25 October 2015; published 28 October 2015

Copyright (C) 2015 by authors and Scientific Research Publishing Inc.

This work is licensed under the Creative Commons Attribution International License (CC BY). http://creativecommons.org/licenses/by/4.0/

(c) (i) Open Access

\begin{abstract}
Many studies had already been conducted to acknowledge the contribution of walking in sustainable urban development. After conducting a literature study, authors identified the 3 (three) keyelements and introduced them as PL.AC.E. (abbreviation of Profile, Activity, and Environment), of the pedestrian. The Pedestrian Profile was defined as a combination of the following key-attributes: age; financial income; physical condition; gender; mobility choice; employment and education; social cultural capital; pedestrian type; and public transportation usage. The Pedestrian Activity was defined from the key-attributes as follow: walking-related purposes; social interaction; walking intensity; walking habits; and transport modes interaction. Then the Pedestrian Environment was defined within key-attributes of: spatial planning; walk-ability; neighborhood livability; traffic safety; pedestrian facilities (hard elements); pedestrian facilities (soft elements); and environmental quality. In this study, authors would assess those key-elements by distributing a questionnaire to a group of freshmen of the Department of Architecture in the University of Kitakyushu, Japan as a trial experiment. Total 58 responses were recorded and then analyzed using correlations type statistical analysis. It was then concluded that there are indications that those key-elements could be addressed in the planning process of a walk-able urban environment. However in order to validate the result, authors would continue to further distribute the questionnaire to various respondents within different case study areas.
\end{abstract}

\section{Keywords}

Walking, Pedestrian, Key-Elements, Key-Attributes, PL.AC.E. 


\section{Introduction}

It is suggested that by improving walking condition and environment, traffic congestion could be avoided, nature could be conserved, and public health and living quality could be improved (Blanco et al., 2009). In other words it is important to improve walking condition and walking environment in order to address current urban issues. Walking environment is a very important subject because of the fact that pedestrian moves slower than motorized vehicle thus it interacts more with the surrounding environment (Sauter et al., 2010). For example, average Japanese walks with the speed ranging from 81 to 93.6 meters per minute (Mateo-Babiano \& Ieda, 2007). With this speed, pedestrian is allowed to be influenced intensively by its walking environment. Another study also found that there are other factors that influence pedestrian such as social environment, sidewalk facilities and activities, building appearances, and personal safety (Brown et al., 2007). There are also other measurable factors that were recommended to improve the design of walking environment such: sidewalks, parking lots, building setbacks, block length, intersection type, and census block density (Parks \& Schofer, 2006). Only from these two literatures alone, authors already could gather various attributes of the walking environment.

Furthermore authors acknowledge that the developments toward the promotion of walking in urban area that focused only on improving the walking environment often fail to encourage people to walk. That is to say that improving the walking environment alone could not improve the walking performance in urban area. Therefore one needs also to elaborate and address the factors of walking condition. Also many studies from various disciplines were already conducted to define the attributes of walking condition that could be improved. A study had concluded that it is important to pay attention to the pedestrian walking behavior which is a combination of individual characteristics, infrastructure, and societal attributes (Tsukaguchi, 2010). Therefore, if we could understand the walking behavior, we might find partly the right solution to improve the walking condition. The purposes of the walking trips and the socio-demographic characteristics also influence the walking experience (Manaugh \& El-Geneidy, 2011). Those are related to the activities in the walking area. Here authors also discovered that many different attributes also need to be addressed in order to improve the walking condition.

Authors argue that this diverse finding of attributes addressing the issues on walking environment and walking condition possibly has distracted the efforts of creating better walkable urban planning and development. It will take an enormous effort and time for them to consider all the attributes that are available. Therefore the main question for this research is how to create a cross-field framework consisting common key-attributes of walking to serve as a measure for urban planning or assessment. Authors acknowledge that the attributes were the outcomes of multi-disciplinary researches, thus authors focus on subjects that are related to urban planning.

For this research purpose, authors already conducted extensive literature reviews of scientific journals and papers as reported in author`s previous paper (Nuzir \& Dewancker, in press) (Table 1). The manuscripts were collected and then a content analysis was conducted to extract all keywords, generate groups of key-elements from the keywords and later to synthesize common attributes in the study of walking. From this literature review, authors concluded that in order to discuss and elaborate the walking phenomenon there are key-elements of Pedestrian Profile, Pedestrian Activity, and Pedestrian Environment which are being introduced by authors as its abbreviation, PL.AC.E. (ProfiLe, ACtivity, Environment). Pedestrian Environment obviously refers to the walking environment, while Pedestrian Profile and Pedestrian Activity elaborate the walking condition.

Authors proposed that the key-element of Pedestrian Profile could be defined by investigating key-attributes as follow: age; financial income; physical condition; gender; mobility choice; employment and education background; social cultural capital; pedestrian type; and public transportation usage. Authors further proposed that the key-element of Pedestrian Activity could be defined by investigating key-attributes as follow (Figure 1): walking-related purposes; social interaction; walking intensity; walking habits; and transport modes interaction. The last but not the least important is the key element of Pedestrian Environment of which could be defined from several key-attributes as follow: spatial planning; walk-ability; neighborhood livability; traffic safety; pedestrian facilities (hard elements); pedestrian facilities (soft elements); and environmental quality.

Authors aim that in future of urban planning process, the key-elements of PL.A.CE. could be emphasized as the framework for planning focuses while the common attributes could become the planning parameters. In the post-occupancy stage, authors would also suggest to value the PL.AC.E. and utilize its key-attributes for detail measurements.

\section{Research Objectives}

By contextually defining and/or re-defining the PL.AC.E., authors suggest that an urban area could be assessed 


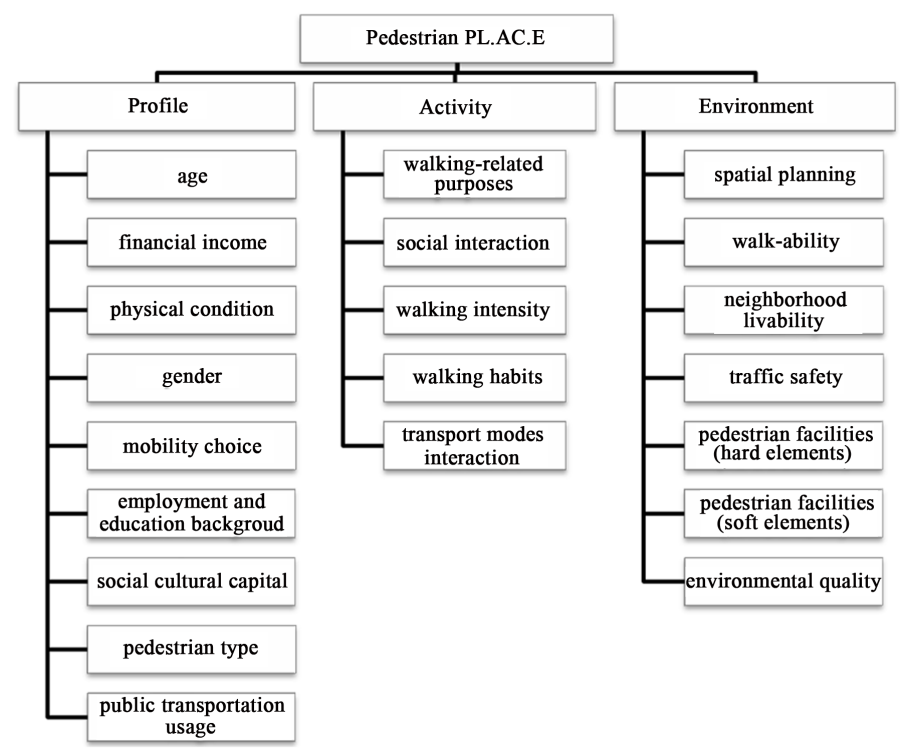

Figure 1. PL.AC.E.'s Key-attributes.

Table 1. The references and its keywords grouping.

\begin{tabular}{|c|c|c|c|}
\hline Keywords & Authors & Correlation & Key-elements \\
\hline $\begin{array}{l}\text { walking; fitnes walking; walking trips; } \\
\text { walking for health; sustainable transport; } \\
\text { soft mobility; image of walking; mobile methods }\end{array}$ & $\begin{array}{l}\text { Addy (2004); Ariffin (2013); Brown (2007); } \\
\text { Forsyth (2009); Galderisi (2010); Greenwald } \\
\text { (2001); Kelly (2011); Leslie (2005); Lindelow } \\
\text { (2014); Naderi (2005); Tsubono (2002); } \\
\text { Tsukaguchi (2010); Tsukaguchi (2011) }\end{array}$ & $\begin{array}{l}\text { general } \\
\text { purpose of } \\
\text { walking }\end{array}$ & \multirow[b]{2}{*}{$\begin{array}{l}\text { Pedestrian } \\
\text { Activity }\end{array}$} \\
\hline $\begin{array}{l}\text { pedestrian attitudes; perceptions; walking } \\
\text { behaviour; incivilities; travel behavior; movement; } \\
\text { stated preference; shopping; crossing compliance; } \\
\text { pedestrian compliance; pedestrian perceptions; } \\
\text { pedestrian behavior; pedestrian travel culture; } \\
\text { pedestrian movement behavior; impulse stops; } \\
\text { pedestrian decision making; } \\
\text { pedestrian traffic; walking to and from }\end{array}$ & $\begin{array}{l}\text { Ariffin (2013); Azmi (2012); } \\
\text { Cervero (1997); Foltete (2007); } \\
\text { Greenwald (2001); Kelly (2011); } \\
\text { Shokoohi (2012); Sisiopiku (2003); } \\
\text { Tajima (2013); Tsukaguchi (2010); } \\
\text { Tsukaguchi (2011); } \\
\text { Wang (2014); Xi (2012) }\end{array}$ & $\begin{array}{l}\text { pedestrian } \\
\text { behaviour }\end{array}$ & \\
\hline $\begin{array}{l}\text { walkability; walkable communities; pedestrian } \\
\text { friendliness; shortest or greenest route; } \\
\text { eco-friendly walk score calculator; accessibility; } \\
\text { pedestrian safety; safety; perceived crash risk }\end{array}$ & $\begin{array}{l}\text { Ariffin (2013); Azmi (2012); Cho (2009); } \\
\text { Cubukcu (2013); Foltete (2007); } \\
\text { Leslie (2007); Lindelow (2014); } \\
\text { Lwin (2011); Manaugh (2011); } \\
\text { Parks (2006); Shay (2003) }\end{array}$ & $\begin{array}{l}\text { compatibility } \\
\text { for walking }\end{array}$ & \multirow[b]{2}{*}{$\begin{array}{l}\text { Pedestrian } \\
\text { Environment }\end{array}$} \\
\hline $\begin{array}{l}\text { built environment; neighborhood; neighbourhood } \\
\text { area; environment; environment and public health; } \\
\text { community facilities; environmental aesthetics; } \\
\text { urban sustainability; urban environment; } \\
\text { public space; sidewalks; landscape preference; } \\
\text { pedestrian networks; pedestrian ways; } \\
\text { neighbourhood environmental quality; } \\
\text { pedestrian landscapes; environmental perceptions; } \\
\text { pedestrian environment; physical environment; } \\
\text { visual attractors; density; crosswalks; } \\
\text { midblock crosswalks; signalized crosswalks }\end{array}$ & $\begin{array}{l}\text { Azmi (2012); Brown (2007); Cervero (1997); } \\
\text { Cho (2009); Ehrenfeucht (2007); Foltete (2007); } \\
\text { Forsyth (2009); Galderisi (2010); Gebel (2011); } \\
\text { Hanan (2012); Kelly (2011); King (2003); } \\
\text { Leslie (2005); Leslie (2007); Lindelow (2014); } \\
\text { Lwin (2011); Manaugh (2011); Naderi (2005); } \\
\text { Parks (2006); Shay (2003); Shokoohi (2012); } \\
\text { Sisiopiku (2003); Wang (2014) }\end{array}$ & $\begin{array}{l}\text { physical } \\
\text { surrounding } \\
\text { for walking }\end{array}$ & \\
\hline $\begin{array}{l}\text { pedestrian/s; lifestyle; lifestyle issues; } \\
\text { human locomotion; active living; } \\
\text { health problems; body weight changes; women; }\end{array}$ & $\begin{array}{l}\text { Addy (2004); Ariffin (2013); Cubukcu (2013); } \\
\text { Dawson (2007); Gebel (2011); Kelly (2011); } \\
\text { Shay (2003); Sisiopiku (2003); } \\
\text { Tajima (2013); Tsukaguchi (2011) }\end{array}$ & $\begin{array}{l}\text { personal } \\
\text { character }\end{array}$ & \multirow[t]{2}{*}{$\begin{array}{l}\text { Pedestrian } \\
\text { Profile }\end{array}$} \\
\hline $\begin{array}{l}\text { physical activity; physical fitness; } \\
\text { physical education; every-day activities }\end{array}$ & $\begin{array}{c}\text { Addy (2004); Forsyth (2009); Gebel (2011); } \\
\text { King (2003); Leslie (2007); } \\
\text { Lindelow (2014); Tsubono (2002) }\end{array}$ & $\begin{array}{l}\text { physical } \\
\text { feature }\end{array}$ & \\
\hline
\end{tabular}


for its existing performances and/or be improved based on its potentials to become a walk-able area. However it is required to examine and to find the best method to utilize this framework. Therefore in this paper, authors assess the possibilities of the utilization of the PL.AC.E. and its key-attributes using a survey questionnaire which is the most used method in the study of walking phenomenon. The purpose is to confirm that it can serve as a measure for urban planning or assessment in promoting a walking-friendly environment. The framework should be able to identify the propensity of each key-attribute in order to understand the characteristic of research subject. The framework also should be able to elaborate the relationship between the key-attributes within each key-element in order to find unique phenomena related to walking. The propensity and the relationship will be valuable information for the planning and assessment process at the early stage.

\section{Method}

The questionnaire was designed to target different kind of respondents and case study areas so then the result could be representing different scenarios for the validation process. This method was selected based on the finding that this is the most common method for data collection in the study of walking phenomenon (Nuzir \& Dewancker, in press). Authors then prepared a trial session for the questionnaire by collaborating with the freshmen (first year) students of the Department of Architecture, the University of Kitakyushu, Japan.

\subsection{Preparation of the Questionnaire}

The questionnaire was prepared based on the key-elements of Pedestrian PL.AC.E. and its key-attributes. Authors generated 3 parts of questions written in Japanese. Part 1 was consisted of 15 questions reflecting keyattributes to understand Pedestrian Profile. The questions were designed as categorical nominal type questions with contents of as follow: public transportation usage; transport mode to work, school, daily market, public facilities, and for recreation; car ownership and usage; motorbike ownership and usage; familiar with the term "Climate Change", "Greenhouse Gases (GHG) or $\mathrm{CO}_{2}$ Emission”, and "Low Carbon Principles or Low Carbon City”; type of living place; reason choosing living place; period of living; and physical activity. Several keyattributes related to respondent's identities were asked separately prior to this part within 8 questions which are: employment status; current address; place of work/school; marriage and number of household member; age; gender; hometown; and nationality.

Then Part 2 was consisted of 25 categorical nominal type questions reflecting key-attributes to understand Pedestrian Activity with contents of as follow: frequent walking location; walking duration; walking purpose; accident with bicycle, car/motorcycle; transports combination; public facilities availability; walking in daytime, night time; walking regularity; walking activity when alone; walking and travel cost; visual attractors; crosswalk attitude; walking route familiarity; common walkway description; favorite walkway part; reason for choosing walking area; walking position adjustment; and interaction with other pedestrians.

Meanwhile Part 3 was consisted of 20 categorical ordinal type questions reflecting key-attributes to understand Pedestrian Environment with contents of as follow: seating place or rest area; pedestrian crossing/bridge; quality of noise environment; street lighting; pedestrian warning/guidance signage; safety (from traffic); security (from crime); access to open spaces or parks; feeling when walking; width of sidewalk; walkway physical condition; greeneries along the sidewalk; walking comfort; cleanliness; access to public transport; pavement; land-use diversity; accessibility for disable person; route network or connectivity; attractiveness of visual P.O.I.; aesthetic; general weather condition in summer; general weather condition in winter; population/neighborhood density; and distance to destinations. Finally the questionnaire was consisted of 68 questions.

\subsection{Data Collection and Analysis}

Following the finalization of the questionnaire, authors conducted trial experiment to assess the questionnaire prior to its distribution to the case study. The trial session was conducted on April $28^{\text {th }}$, 2015 between 9.15 A.M. until 9.45 A.M. at the CAD Room of the Department of Architecture, the University of Kitakyushu. 61 sets of questionnaire print-out were prepared based on the number of course participant and distributed to the students. Authors gave brief explanation about the research purposes prior to distribution. After the designated time finished, only 58 questionnaires were returned. Then statistical analysis was conducted using the SPSS (Statistical Package for Social Sciences) software version 17. After inputting the responses, authors started the first stage of 
data analyzing by conducting a descriptive statistical analysis with the frequency procedure. The purpose was to summarize the pattern of the responses in order to understand the characteristic of research subject.

Furthermore to get better understanding of the responses, authors conducted the second stage of data analysis within a form of bivariate analysis using the SPSS software. This was done by looking at pairs of key-attributes on how they interact or are different. Authors arranged the pair by selecting one attribute of one key-element and another attribute of another key-element. Therefore there were 3 groups of analysis: Pedestrian Profile paired with Pedestrian Environment, Pedestrian Profile paired with Pedestrian Activity, and Pedestrian Environment paired with Pedestrian Activity.

The purpose of this method is to assess the association between two category type questions using crosstabulation procedure. This association is useful it to elaborate the relationship between the key-attributes within each key-element in order to find unique phenomena related to walking. Authors would only refer to the association which has Pearson Chi-square $\left(\mathrm{X}^{2}\right)$ not more than 0.05 , meaning that the probability level is at $95 \%$. Also authors noticed that in order to be reliable, only maximum $20 \%$ of the cells was allowed to have expected count less than 5 . However authors would still consider up to $50 \%$ for fairly reliable result. And then authors would discuss possible explanation of the outcomes.

\section{Results}

\subsection{Descriptive Analysis Using Frequency Procedure}

A descriptive analysis were conducted and defined separately within each key-element of Pedestrian Profile, Activity, and Environment. The objective of this analysis was to identify the propensity of each key-attribute in order to understand the characteristic of research subject in the context of each key-element.

\subsubsection{Pedestrian Profile}

As for the first part, the questions focused on the Pedestrian Profile and also included questions about the respondent identities. There were several general summaries as described in the following paragraphs. Regarding the age, since the respondents were 1st year university students, thus the age represented mainly 1 group of responses which is between 1 - 20 years old (57 responses). As for the gender, the respondents were divided relatively in balance which was between $60.3 \%$ of male students and $39.7 \%$ of female students. Obviously all was the University of Kitakyushu students.

All of the respondents were single or unmarried. Also all was Japanese. The students only live either in apartment/mansion (65.5\%) or detached house (34.5\%) (Figure 2). And mostly they live inside of Kitakyushu city (76.4\%) or at the surrounding cities inside Fukuoka prefecture (23.6\%), as seen in Figure 3. Yet only 5.2\% of respondents were originally from Kitakyushu city. In Kitakyushu city mostly they live in Yahatanishi Ward (59.3\%). In fact more than half (53.4\%) lives in their current address only less than 1 month. Refer to Figures 4-6.

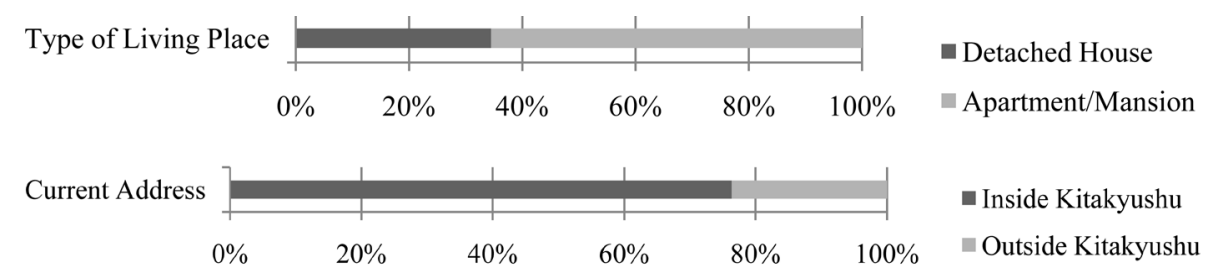

Figure 2. Percentage of type of living place (above) and current address (below).

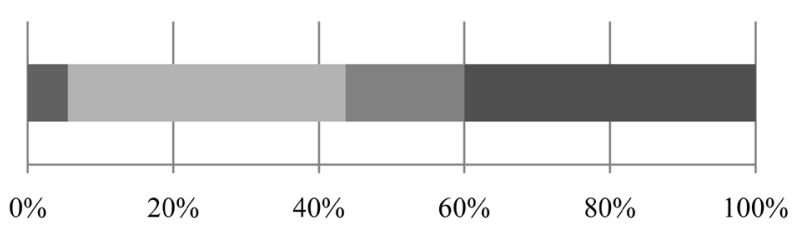
Inside Kitakyushu
Outside Kitakyushu but still inside Fukuoka perfecture
Outside Fukuoka perfecture but still inside Kyushu
- Outside Kyushu

Figure 3. Percentage of hometown. 


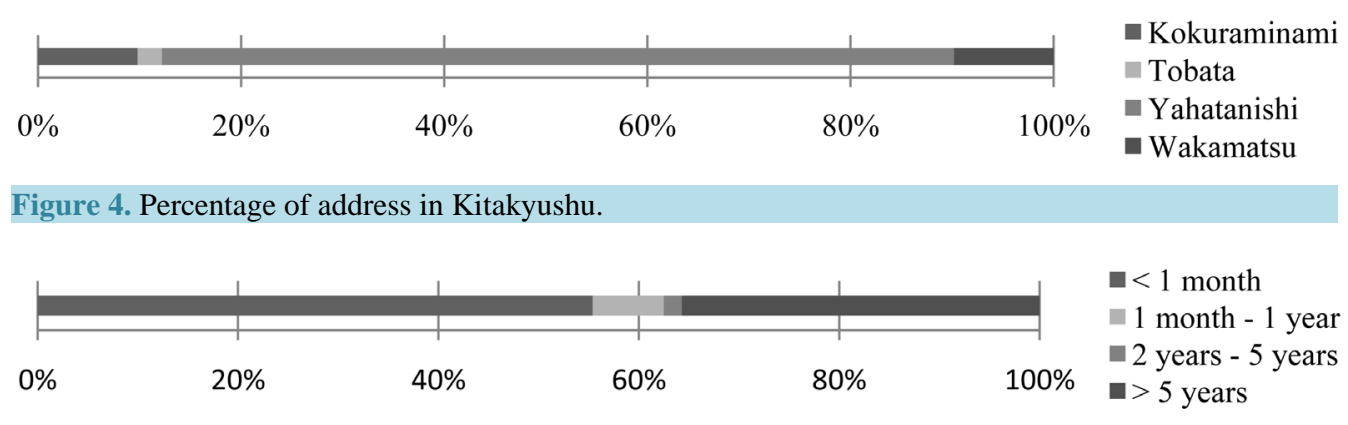

Figure 5. Percentage of living period.

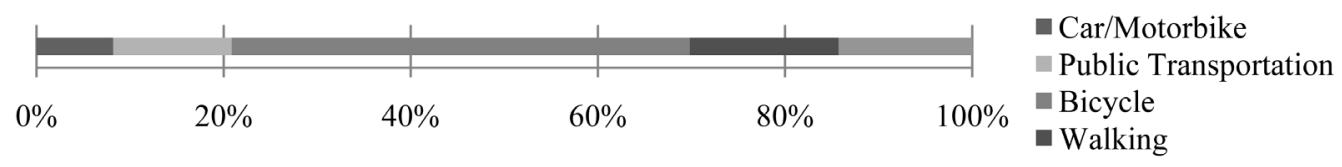

Figure 6. Percentage of mobility choice.

For the key-attributes of mobility choice, there were 4 (four) scenarios provided such as: to work; to school/ university; to daily market; to public facility; and for recreation. From total responses of the mobility choice, bicycle (49\%) was recorded as the main transport mode, followed by walking (15.9\%), and public transportation (12.7\%). Refer to Figure 7.

The next response was about the vehicle ownership and usage. In total, $89.6 \%$ of the students do not own and cannot use the motorized vehicles. Authors also found there were 1 student who does not want to own and/or use car at all and 7 students who do not want to own and/or use motorbike at all. Please see Figure 8.

Despite of the fact that mostly the students practice low carbon urban mobility method i.e. cycling, their awareness level about several terminologies of environmental issues, such as Climate Change, Greenhouse Gases (GHG) or $\mathrm{CO}_{2}$ Emission, and Low Carbon Principles or Low Carbon City, was quite low, as in Figure 9.

As for the physical condition, authors found that more than half were doing the following routine such as: every day (6.9\%), 1 - 2 times a week (43.1\%), or not regular but often (25.9\%), as seen on Figure 10. Another summary was that only less than half used public transportation in daily basis. Please refer to Figure 11.

\subsubsection{Pedestrian Activity}

From the questions related to the walking habits, the respondents mentioned their frequent walking location to be mostly in their neighborhood (43.9\%) and around university (29.8\%). Please refer to Figure 12. In regard with the preference of walking period of time (Table 2 and Table 3), it was indicated that walking is undesirable in night time, as seen on Figure 13. A concern regarding safety from traffic and crime was only mentioned on walking in night time.

As for the question regarding the activity when walking alone, "doing conversation by phone or using smartphone" (23.2\%) and "looking at the surrounding" (23.2\%) were commonly selected after the answer of "doing nothing particular or thinking" (39.3\%), as seen in Figure 13. Mainly the respondents walk from minimum 5 minutes to maximum half an hour per a single walking trip of which was divided between 15 minutes to 30 minutes as the most common duration (41.4\%) followed by between 5 minutes to 15 minutes (36.2\%). Please see Figure 14. Nearly half of the respondents walk at least 5 days per week (46.6\%), as seen in Figure 15.

Since the respondents were students, nearly half of them mentioned their walking purpose was to go to university (44.8\%). Most of them walk to reduce their travel cost (60.3\%). This was related to another finding that more than half of the respondents stated that they can find public facilities and/or public station hub within their walking area. For complete result of these findings, please refer Figures 16-18.

Furthermore authors found that there were conflicts between pedestrian and cyclist although the common responses were mainly seldom (37.9\%) and sometimes (31\%), as seen in Figure 19. In term of transport modes combination, walking was often combined either with public transportation (41.1\%) or with bicycle (35.7\%). Please refer to Figure 20. 


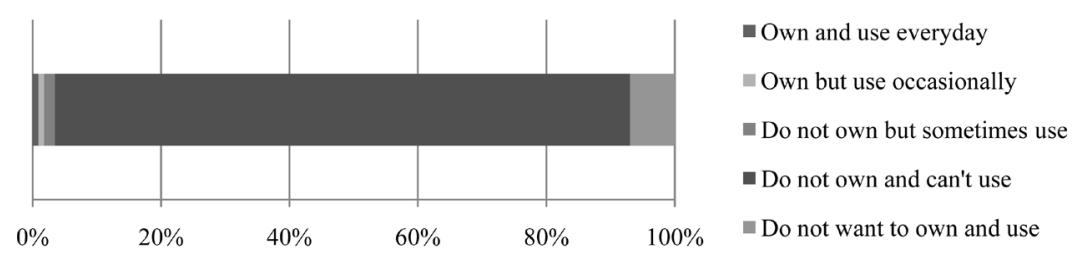

Figure 7. Percentage of vehicle ownership and usage.

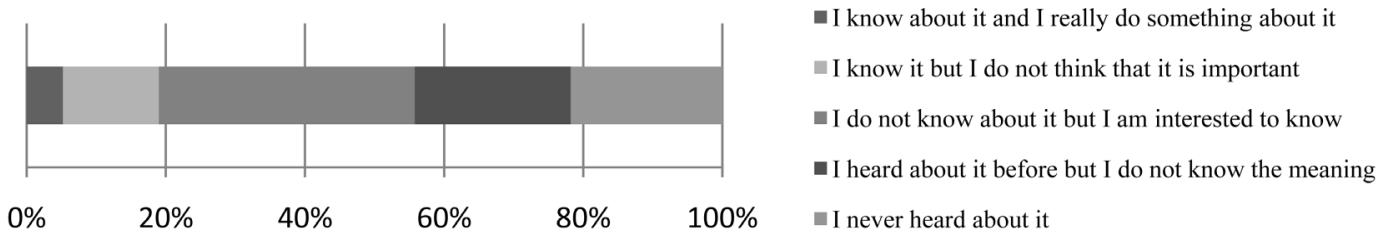

Figure 8. Percentage of environmental issue awareness.

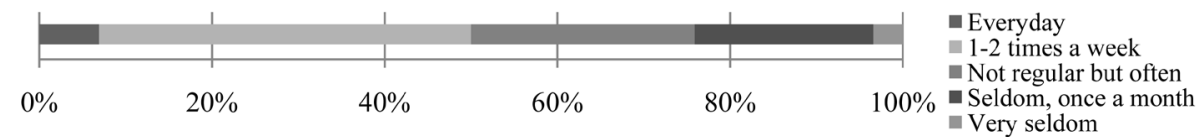

Figure 9. Percentage of physical activity.

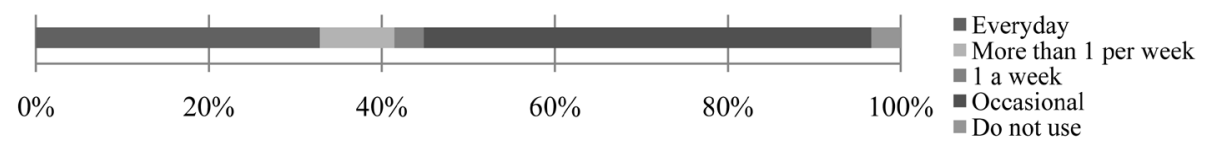

Figure 10. Percentage of public transportation usage.

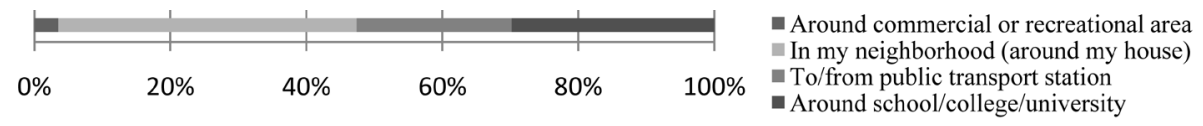

Figure 11. Percentage of frequent walking location.

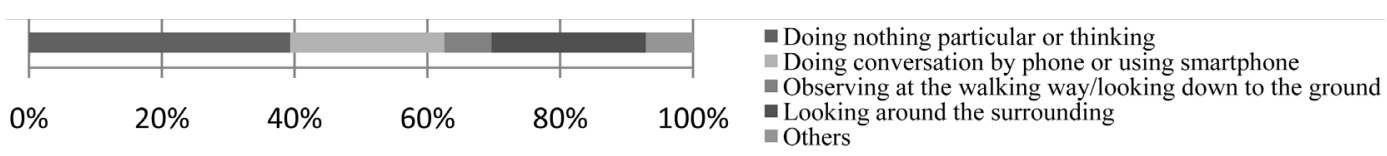

Figure 12. Percentage of activity when walking alone.

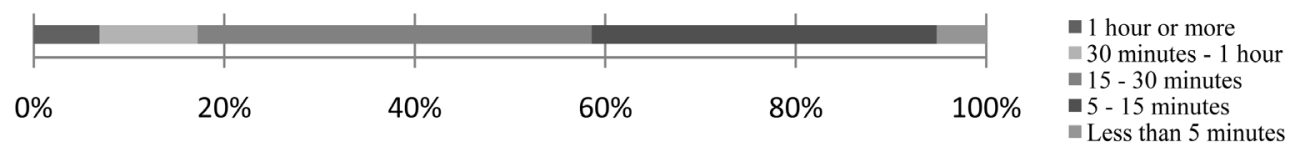

Figure 13. Percentage of walking duration.

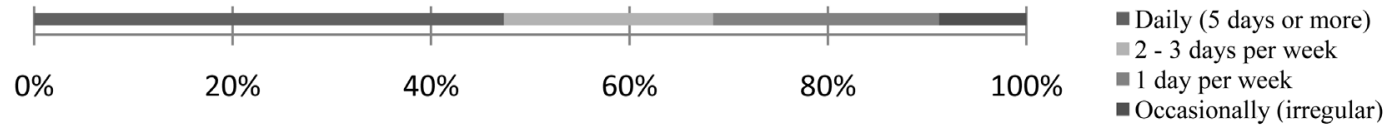

Figure 14. Percentage of walking regularity/routine.

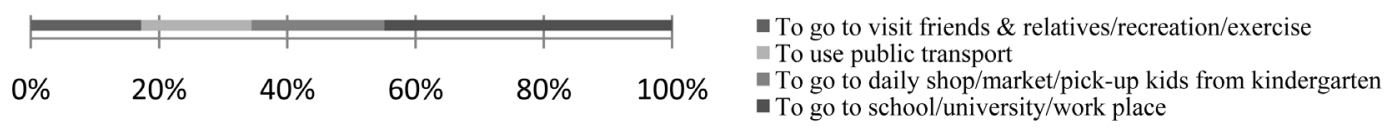

Figure 15. Percentage of frequent walking purpose. 


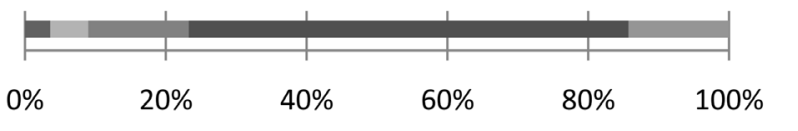

I do not walk and I do not mind high travel cost I do not walk but my travel cost is always low I walk only when I do not have money

- I walk to reduce my travel cost

I walk although I can afford higher travel cost

Figure 16. Percentage of relation between walking and travel cost.

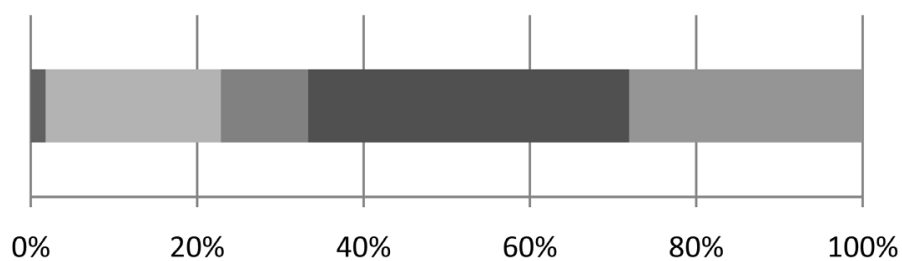

- I cannot find all types and I also cannot find bus stop or train station

I cannot find all types but I can find bus stop or train station

I can find at least 1 type but I cannot find

bus stop or train station

I can find at least 1 type and also bus stop or train station

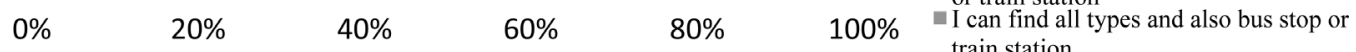

Figure 17. Percentage of public facilities availability.

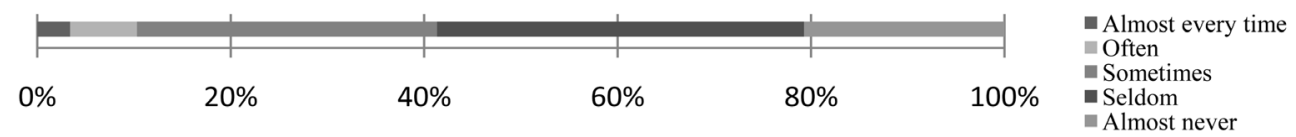

Figure 18. Percentage of conflict with bicycle.

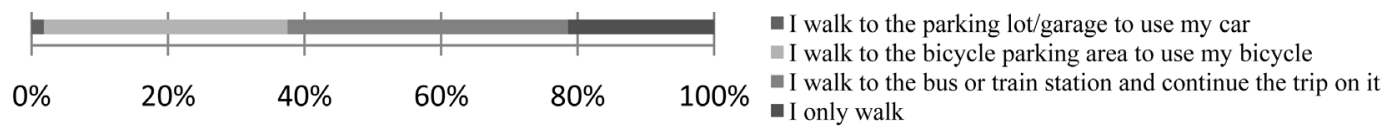

Figure 19. Percentage of relation between walking and travel cost.

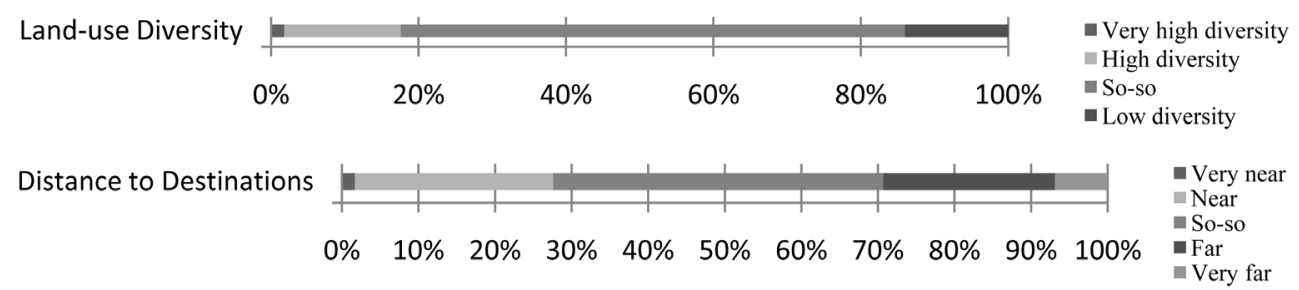

Figure 20. Land-use diversity (above) and distance to destinations (below).

Table 2. Frequency of walking in daytime.

\begin{tabular}{|c|c|c|c|}
\hline Validity & Responses & Frequency & Percent \\
\hline \multirow{5}{*}{ Valid } & Yes, I like it because it is safe, comfortable, and nice place to walk & 15 & 25.9 \\
\hline & Yes, I like it because it is easy to walk to everywhere & 18 & 31.0 \\
\hline & It is okay, I walk whether I like it or not & 20 & 34.5 \\
\hline & No, I do not like because it is not comfortable (inconvenient weather, bad facility, etc.) & 4 & 6.9 \\
\hline & Total & 57 & 98.3 \\
\hline Missing & 0 & 1 & 1.7 \\
\hline
\end{tabular}

Table 3. Frequency of walking in night time.

\begin{tabular}{|c|c|c|c|}
\hline Validity & Responses & Frequency & Percent \\
\hline \multirow{6}{*}{ Valid } & Yes, I like it because it is safe, comfortable, and nice place to walk & 9 & 15.5 \\
\hline & Yes, I like it because it is easy to walk to everywhere & 17 & 29.3 \\
\hline & It is okay, I walk whether I like it or not & 19 & 32.8 \\
\hline & No, I do not like because it is not comfortable (inconvenient weather, bad facility, etc.) & 5 & 8.6 \\
\hline & No, I do not like because it is not safe (from traffic and crime) & 7 & 12.1 \\
\hline & Total & 57 & 98.3 \\
\hline Missing & 0 & 1 & 1.7 \\
\hline
\end{tabular}




\subsubsection{Pedestrian Environment}

The part of Pedestrian Environment was designed differently. The respondents were asked about their opinion on their walking area in relation to different key-attributes and to response within certain scale measurement of 1 to 5 which refers from highest positive response to lowest negative response respectively with the "so-so" response in between. When responding to the key-attributes of spatial planning features such as the land-use diversity and distance to destinations, the outcome of "so-so" answer is very high (54.4\%) compared to others. Please refer to Figure 21.

As for the key-attributes of walkability, several questions were generated and results were as the following. First attribute was "feeling when walking", which resulted that more than half of the respondents had either "good" (43.1\%) or "very good" (17.2\%). The next attribute was "walking comfort", which resulted that more than half of the respondents felt comfortable when walking, consisted of "good" (37.9\%) and "very good" (19\%). But then authors found that most of the respondents think that the access to public transport was not good, from "so-so" (40.4\%), "bad" (19.3\%), to "very bad" (1.8\%). And also 84.4\% of the respondents think that the environment is not accessible by a disable person, from "so-so" (54.4\%) to "inaccessible" (31.6\%). However, the respondents think that the route connectivity was either very good (50\%) or good (5.2\%). And a part of the respondents do feel uncomfortable to walk during summer (16.1\%) and winter (14.3\%). Please refer to Figure 22 for complete result of walkability key-attributes.

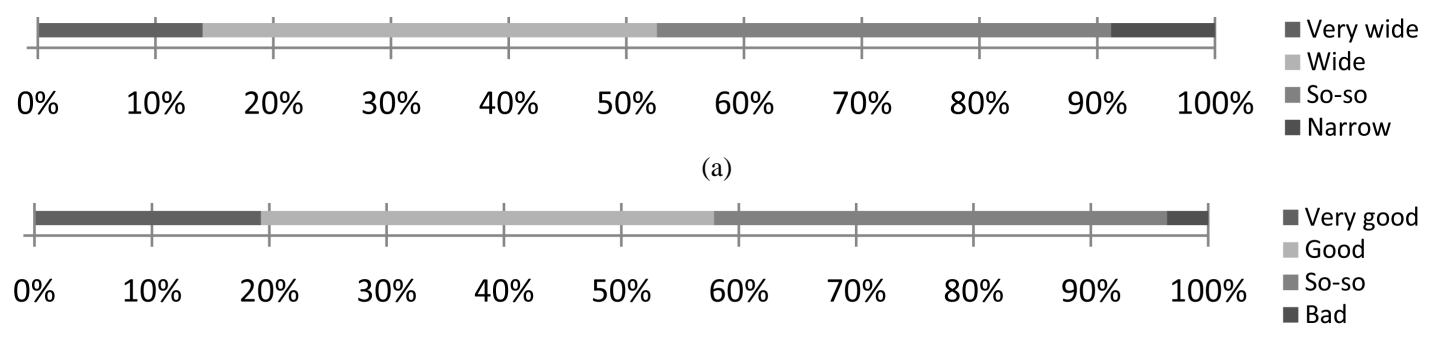

(b)

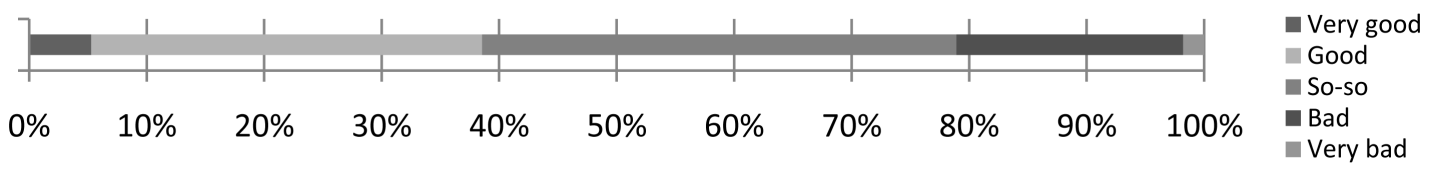

(c)

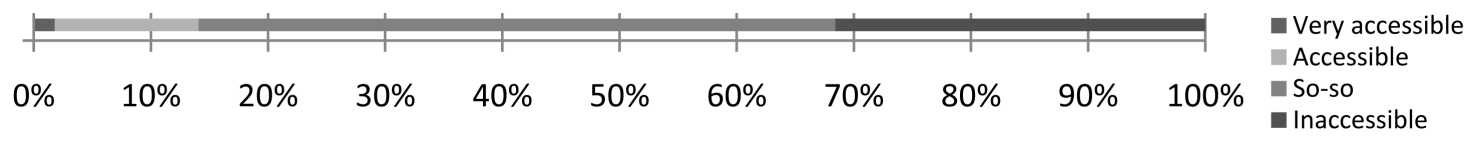

(d)

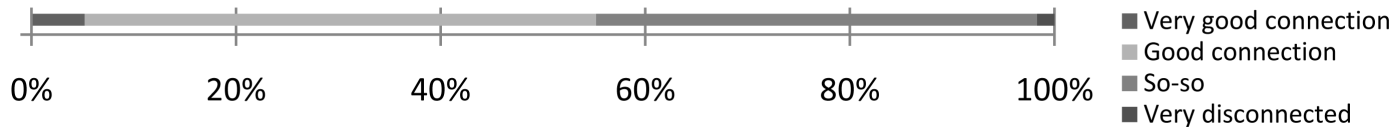

(e)

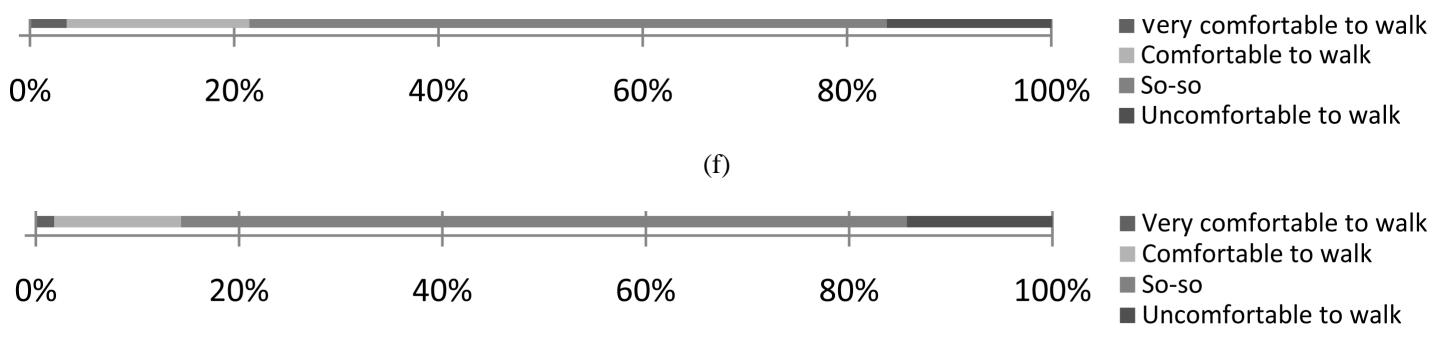

(g)

Figure 21. Feeling when Walking (a); Walking Comfort (b); Access to Public Transport (c); Accessible for Disable Person (d); Route Connectivity (e); Walking in Summer (f); and Walking in Winter (g). 


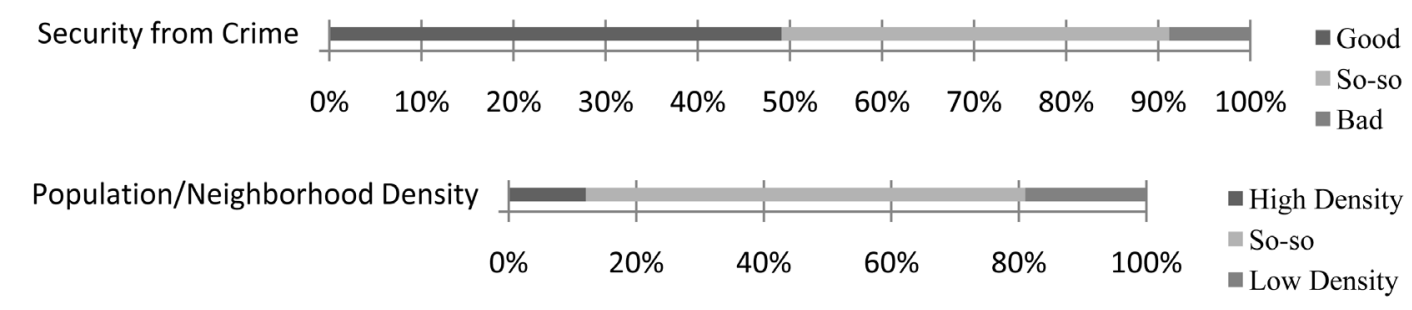

Figure 22. Security from crime (above) and population/neighborhood density (below).

Also another interesting finding was that for the key-attributes of neighborhood livability, only $49.1 \%$ of the respondents really think that the level of security from the crime of their neighborhood was good. As for another key-attribute which is the population or neighborhood density, the response of "so-so" was resulted the most with $69 \%$. Please refer to Figure 23. Then for the traffic safety attributes, the respondents confirmed that the pedestrian crossings or bridges were mostly available in every intersection regardless of the condition with $44.8 \%$ in good condition and $13.8 \%$ not in good condition. And in general, only $39.7 \%$ of respondents think that the traffic safety was good and 3.4\% thinks that the traffic safety was very good. Please refer to Figure 24 .

In relation to the pedestrian facilities especially the hard elements, the results were summarized as the following. Only $15.5 \%$ of respondents stated that there were no seating places or rest areas. Only $12.3 \%$ of respondents stated that there were badly maintained street lightings. Only $1.8 \%$ of respondents stated that pedestrian warning/guidance signage was invisible. As for the width of the sidewalk, the most responses were wide (38.6\%) and very wide (14\%). Then as for the physical condition of the walkway, the most responses were good (38.6\%) and very good (15.8\%) maintenance. However in contradiction only $40.4 \%$ of respondents stated that the pavement was in good and very good maintenance, while the rest of respondents stated "so-so" or even bad maintained. Please refer to Figure 25. As for the attributes of the soft elements of the pedestrian facilities, authors found that only $59.7 \%$ of the respondents were satisfied with the access to open spaces or parks. And also only 56.2\% of respondents were satisfied with the greeneries along the sidewalk. Please refer to Figure 26.

Another finding in relation to the key-attributes of the environmental quality was that although $46.5 \%$ of respondents stated that the attractiveness of visual point of interests was good, the rest of respondents stated "so-so" and even the opposite. Only $41.4 \%$ of respondents stated that the aesthetic value of the area was good, while the rest of respondents stated "so-so" and even the opposite. Furthermore there were only $60.3 \%$ of respondents stated that the pedestrian areas were clean. Please refer to Figure 27.

\subsection{Bivariate Analysis Using Crosstabulation Procedure}

Hereinafter a bivariate analysis was conducted towards pairs of key-attributes from different key-elements. There were 3 groups of analysis such as Pedestrian Profile with Pedestrian Environment, Pedestrian Profile with Pedestrian Activity, and Pedestrian Environment with Pedestrian Activity. Authors tried to find pairs that were significantly related or associated based on the Pearson Chi-Square (X2) test. If the result of 2-sided Asymptotic Significance ( $p$-value) shows the value of less than 0.05 then it means that there are significant relationships. The results would also be considered reliable if they have maximum 50\% percentage of the cells that have expected count less than 5 . The objective of this analysis was to elaborate the relationship between the keyattributes within each key-element in order to find unique phenomena related to walking

\subsubsection{Pedestrian Profile Paired with Pedestrian Environment}

There were several pairs of key-attributes from the group of the Pedestrian Profile and the Pedestrian Environment that had significant associations. The key attribute of "current address" was mostly associated with other attributes from Pedestrian Environment, such as: street lighting, security (from crime), width of sidewalk, walking comfort, cleanliness, and pavement. And the key-attribute of "type of living place" was associated with: cleanliness, weather condition in summer, and distance to destinations. Please refer to Table 4.

From the analysis using crosstabulation procedures, authors could acknowledge several relationships as follows. $51.2 \%$ of the students who currently live inside Kitakyushu stated that the street lighting in their walking area was in good maintenance, but only $15.4 \%$ of the students who live in the neighboring city of Kitakyushu stated the same. Only $2.4 \%$ of students who currently live in Kitakyushu stated that the security 
Pedestrian Crossing

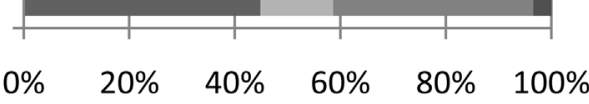

$0 \%$

$20 \%$

$100 \%$

Available but not in a good condition

So-so

- Available only in few places

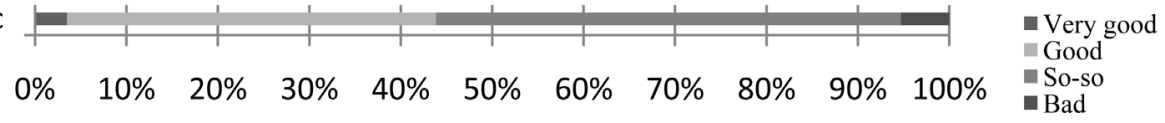

Figure 23. Pedestrian crossing/bridge (above) and safety from traffic (below).

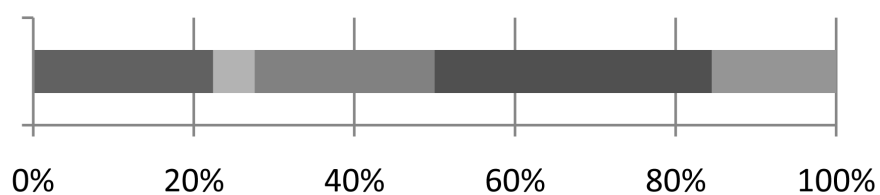

(a)

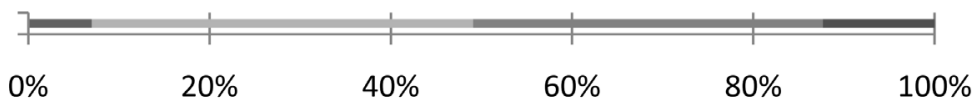

(b)

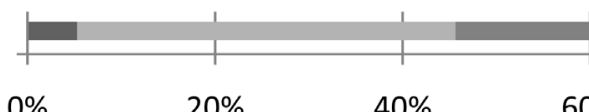

$0 \%$

$20 \%$

$40 \%$

$60 \%$

(c)

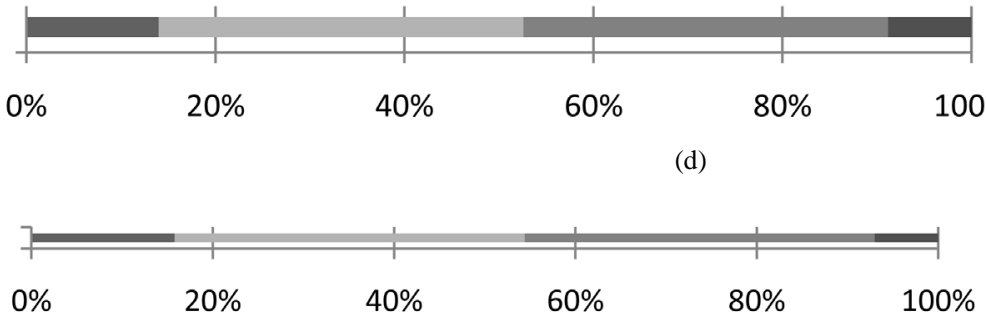

(e)

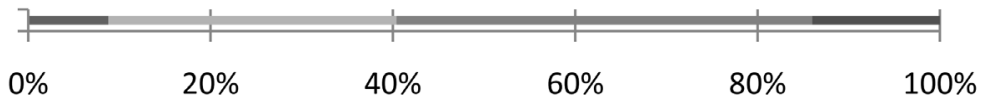

(f)
- Available in good condition in many places

Available but not in a good condition

- So-so

- Available only in few places

Unavailable
- Very good maintenance

Good maintenance

- So-so

- Bad maintenance

- Very visible Visible

So-so

- Invisible

- Very wide $\quad$ Wide

- So-so

- Narrow

- Very good maintenance

Good maintenance

So-so

- Bad maintenance

- Very good maintenance

Good maintenance

So-so

- Bad maintenance

Figure 24. Seating place/rest area (a); Street Lighting (b); Pedestrian Warning/Guidance signage (c); Width of Sidewalk (d); Walkway physical condition (e); and pavement (f).

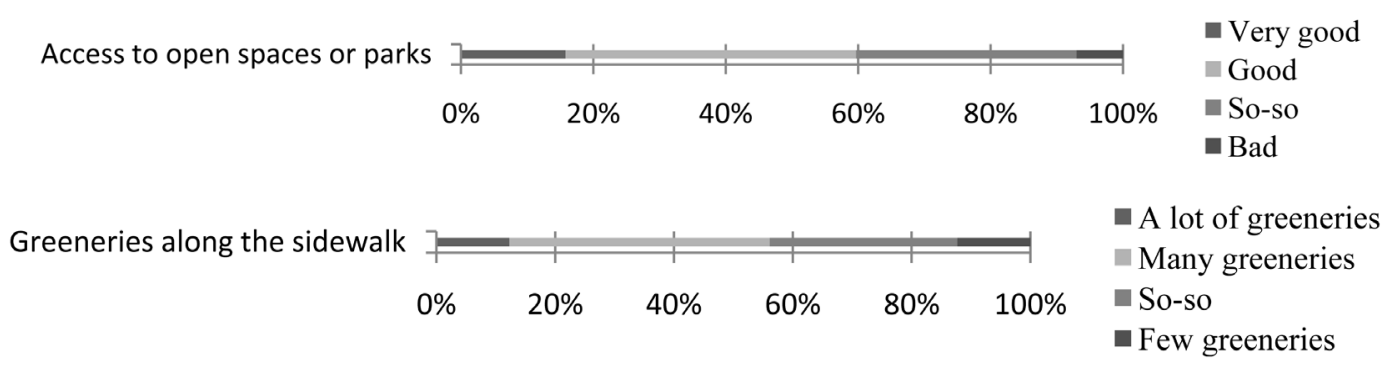

Figure 25. Access to open spaces/parks (above) and greeneries along the sidewalk (below). 


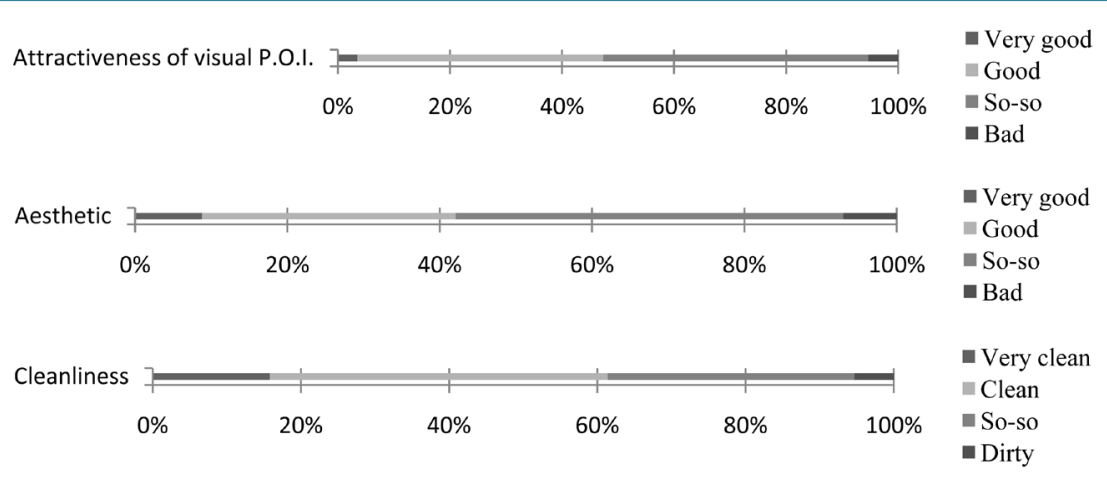

Figure 26. Attractiveness of visual point of interests (top), aesthetic (middle), and cleanliness (bottom).

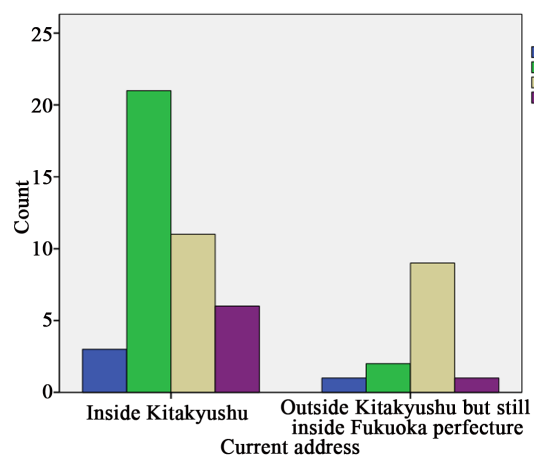

(a)

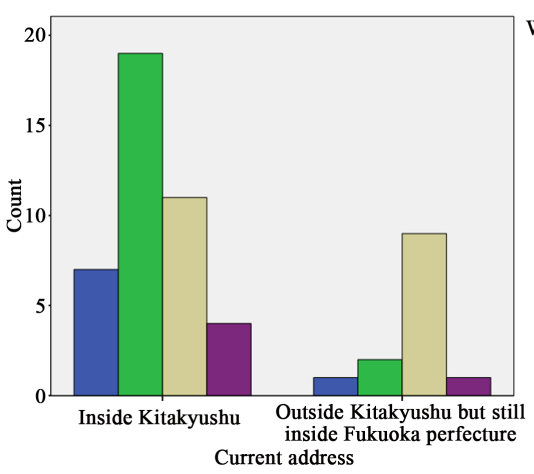

(c)

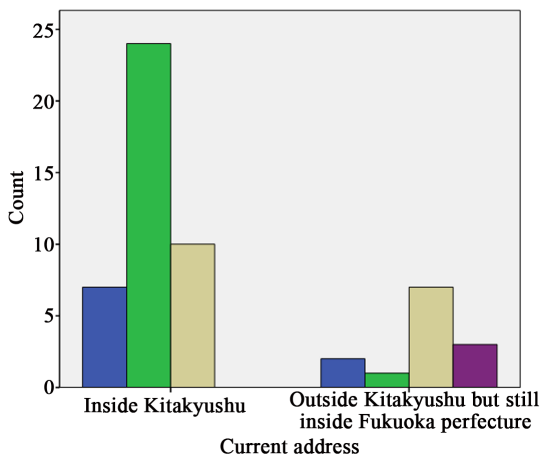

(e)
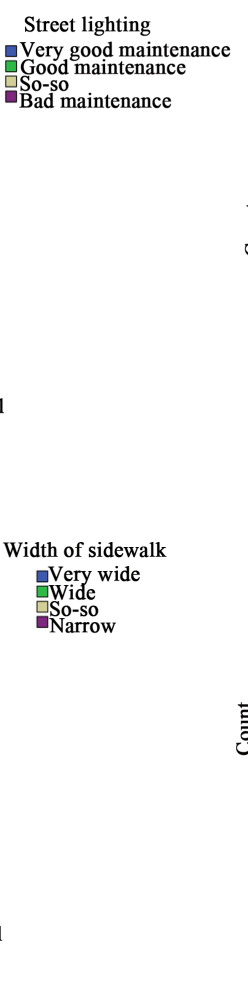

Cleanliness

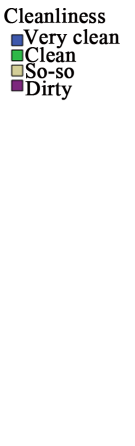

Very clea
Clean

Dirty

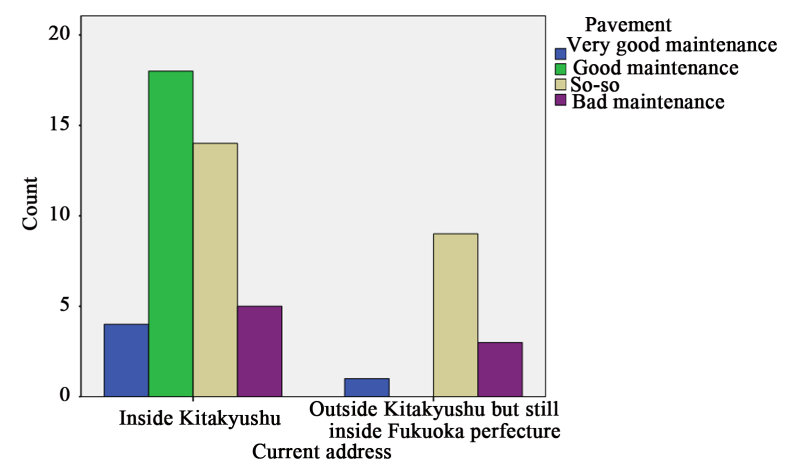

(f)

Figure 27. Current Address-Street lighting (a), Current Address-Security from crime (b); Current Address-Width of sidewalk (c); Current Address_-Walking comfort (d); Current Address_Cleanliness (e); \& Current Address—Pavement (f). 
Table 4. Overall p-value scores of selected pairs of pedestrian profile-pedestrian environment.

\begin{tabular}{|c|c|c|c|}
\hline Pedestrian Profile & Pedestrian Environment & Pearson Chi-Square & Expected Count $<5$ \\
\hline Current address & Street lighting & 0.043 & $50 \%$ \\
\hline Current address & Security (from crime) & 0.004 & $33.3 \%$ \\
\hline Current address & Width of sidewalk & 0.049 & $50 \%$ \\
\hline Current address & Walking comfort & 0.002 & $50 \%$ \\
\hline Current address & Cleanliness & 0.001 & $50 \%$ \\
\hline Current address & Pavement & 0.024 & $50 \%$ \\
\hline Type of living place & Cleanliness & 0.034 & $37.5 \%$ \\
\hline Type of living place & General weather condition in summer & 0.029 & $50 \%$ \\
\hline Type of living place & Distance to destinations & 0.029 & $50 \%$ \\
\hline
\end{tabular}

(from crime) in their walking area was bad, but in the other hand, 30.8\% of students who live in the neighboring city of Kitakyushu stated the same. Similar results were also generated for walking comfort, width of the sidewalk, cleanliness and pavement. Please refer to Figure 28.

Meanwhile as for the association of "type of living place" with "cleanliness", $50 \%$ of students who live in detached houses stated that their walking area is clean. But only $24.3 \%$ of students who live in apartments or mansions stated the same. However during summer time, $30 \%$ of the students who live in detached house felt uncomfortable to walk, while only $8.3 \%$ of the students who live in apartments or mansions also felt uncomfortable to walk. Also $20 \%$ of students who live in detached houses stated that their destinations are very far, compared with none of the students who live in apartments or mansions said the same. Please see Figure 28.

\subsubsection{Pedestrian Profile Paired with Pedestrian Activity}

There were several pairs of key-attributes from the group of Pedestrian Profile and Pedestrian Activity that had significant associations. However the associations were lesser than the associations between Pedestrian Profile and Pedestrian Environment. The key-attribute of "current address" was highly associated with the key-attribute of "frequent walking location", while "gender" was associated with "favorite walkway part". The key-attribute of "type of living place" was associated with other key-attributes such as: frequent walking location, other transports combination with walking, and cross-walk attitude. Please see Table 5 for overall p-value scores.

As for the frequent walking location, mostly students who recently live in Kitakyushu frequently walked in their neighborhood $(51.2 \%)$ or around the university (34.1\%). On the other hand, students who live in neighboring cities often walked to/from public transport station (61.5\%). $30.3 \%$ of the male students stated that they preferred to walk on the far side of the road for vehicle and this was the highest result. Meanwhile $50 \%$ of the female students did not have preference of the walkway part. The similarity was that both, $21.2 \%$ of the male students and $27.3 \%$ of the female students, preferred to walk near to the greeneries in general. The difference was that $24.2 \%$ of the male students preferred to walk along the middle part of the pedestrian area, while none of the female students preferred the same. Please refer to Figure 29.

The students who live in detached houses frequently walked to or from public transport stations (42.1\%), around their school/college/university (31.6\%), or in their neighborhood or around their houses (26.3\%). Meanwhile the students who live in apartments or mansions mostly walked in their neighborhood or around their houses (52.6\%). However, although there were 5.3\% of the students who live in apartments that walked to commercial or recreational area, none of the students who live in detached houses stated the same. And then as for the association between "type of living place" with "other transports combination with walking”, $52.6 \%$ of the students who live in detached houses combined walking with public transports and $42.1 \%$ combined walking with cycling. On the other hand, the students who live in apartments or mansions mostly combined walking with public transports (35.1\%), cycling (32.4\%), or only walking (32.4\%). Furthermore the relation between "type of living place" and "cross-walk attitude" was shown by the results as follow. As for the students who live in detached houses, $35 \%$ looked for sign but sometimes ignore when no traffic or late night, $25 \%$ looked for sign 


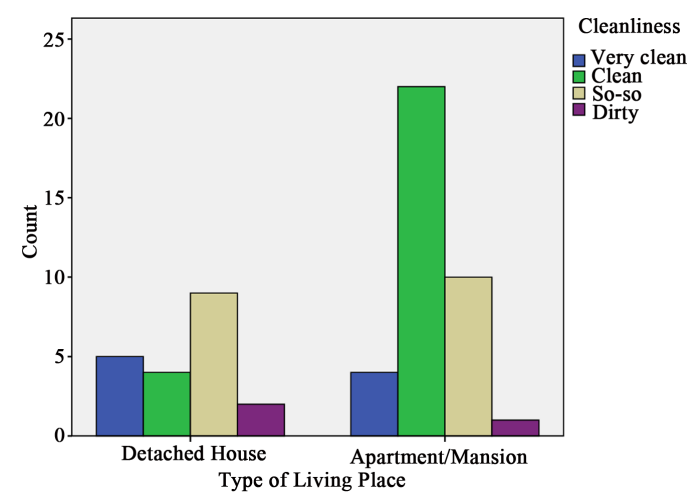

(a)

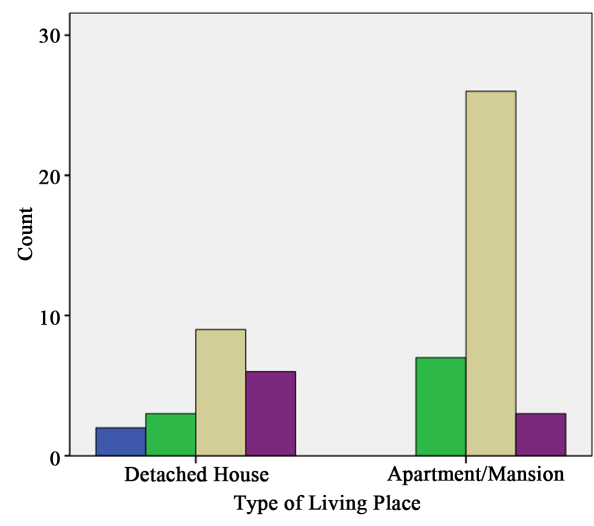

(b)

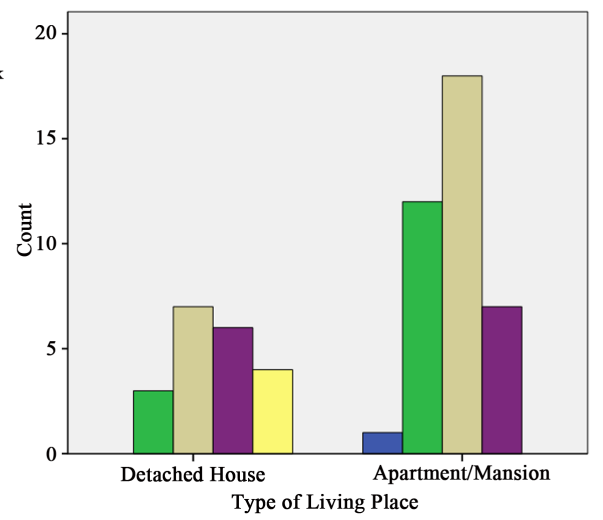

(c)

Figure 28. Type of living place-cleanliness (a); type of living place-weather condition in summer (b); and type of living place-distance to destinations (c).

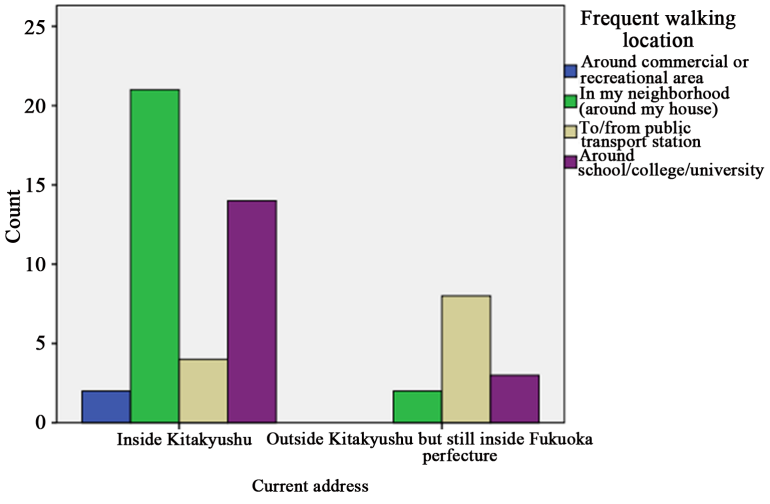

(a)

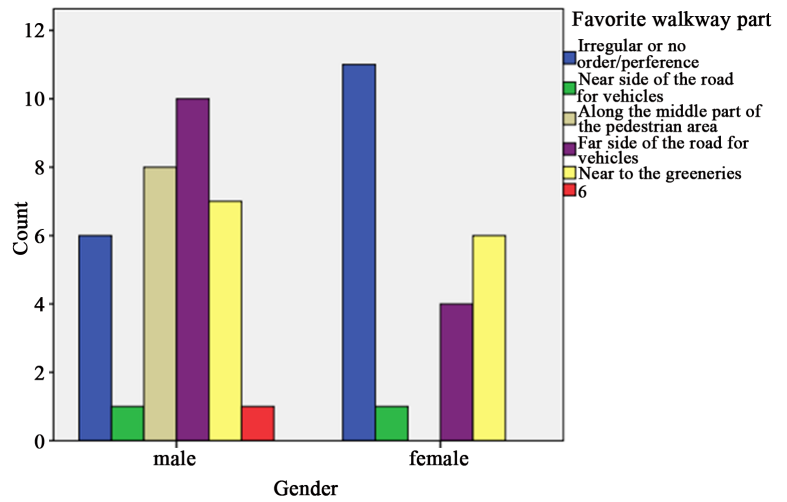

(b)

Figure 29. Current address—-frequent walking location (a); gender-favorite walkway part (b).

Table 5. Overall p-value scores of selected pairs of pedestrian profile-activity.

\begin{tabular}{cccc}
\hline Pedestrian Profile & Pedestrian Activity & Pearson Chi-Square & Expected Count $<5$ \\
\hline Current address & Frequent walking location & 0.001 & 0.044 \\
Gender & Favorite walkway part & 0.053 & $30 \%$ \\
Type of living place & Frequent walking location & 0.025 & $37.5 \%$ \\
Type of living place & Other transports combination with walking & 0.011 & $50 \%$ \\
Type of living place & Cross-walk attitude & \\
\hline
\end{tabular}


and always follow, 25\% did not wait for sign and walk when there is no traffic, and 15\% looked for sign but sometimes ignore when in hurry. In contrast, mostly the students who live in apartments of mansions looked for sign and always follow (63.2\%). Please refer to Figure 30.

\subsubsection{Pedestrian Profile Paired with Pedestrian Activity}

There were several key-attributes of Pedestrian Environment that had significant associations with key-attributes of Pedestrian Activity but only 2 (two) pairs that could be considered reliable, as seen from the percentages of expected count that is less than 5 (five) of which actually should be maximum $50 \%$. The pairs which had the lowest percentage were "pedestrian crossing/bridge"-“walking in daytime”, and also "aesthetic"-“other transports combination with walking”. Please refer to Table 6.

None of the students said that they like to walk in the area where the pedestrian crossings or bridges were only available in few places. But there were $7.7 \%$ of the students who said that although the pedestrian crossings or bridges were available in good condition in every intersection, it was still not comfortable for them to walk in the area. 52\% of the students, who said that the aesthetic value of their walking area was good, only walked along their walking area and did not combine walking with other transports. On the other hand, the "so-so" responses were mostly acquired from students who combined walking with public transports (55.2\%) and with cycling (37.9\%). Please refer to Figure 31.

\section{Discussion}

This experiment was conducted toward the students of the Faculty of Environmental Engineering of the University of Kitakyushu of which its campus is located in the area of Hibikino, within the ward of Wakamatsu

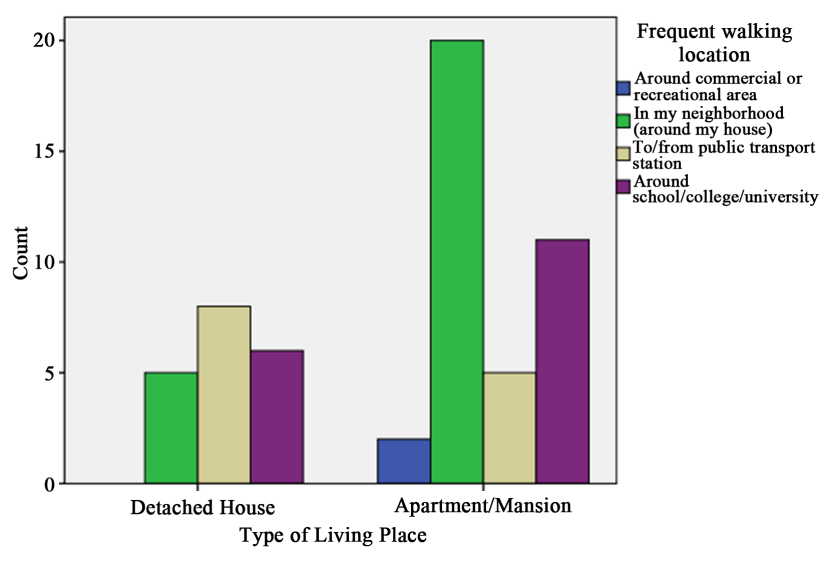

(a)

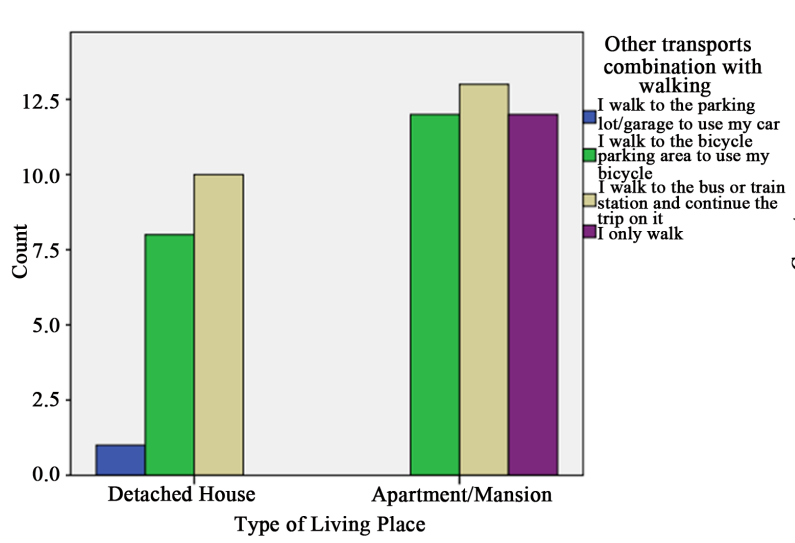

(b)

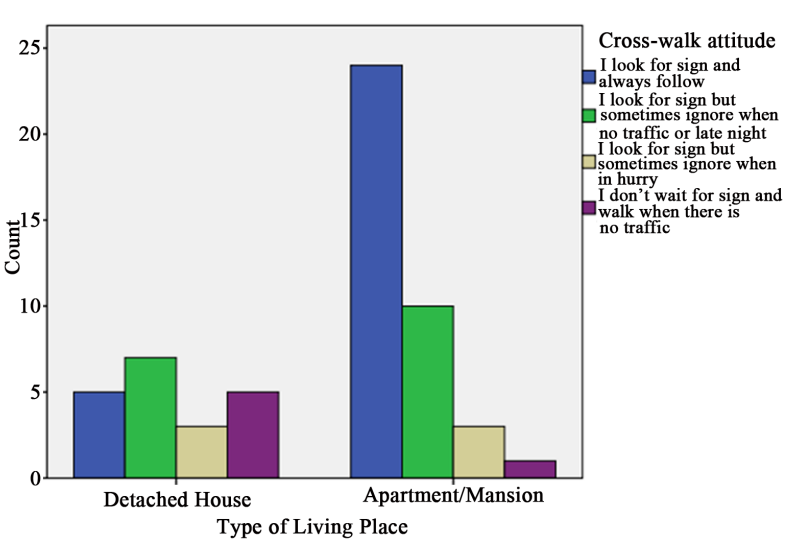

(c)

Figure 30. Type of living place — frequent walking location (a); type of living place-other transports combination with walking (b); type of living place-cross-walk attitude (c). 


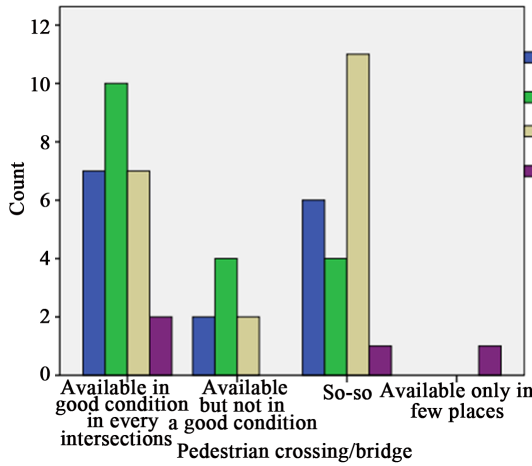

(a)

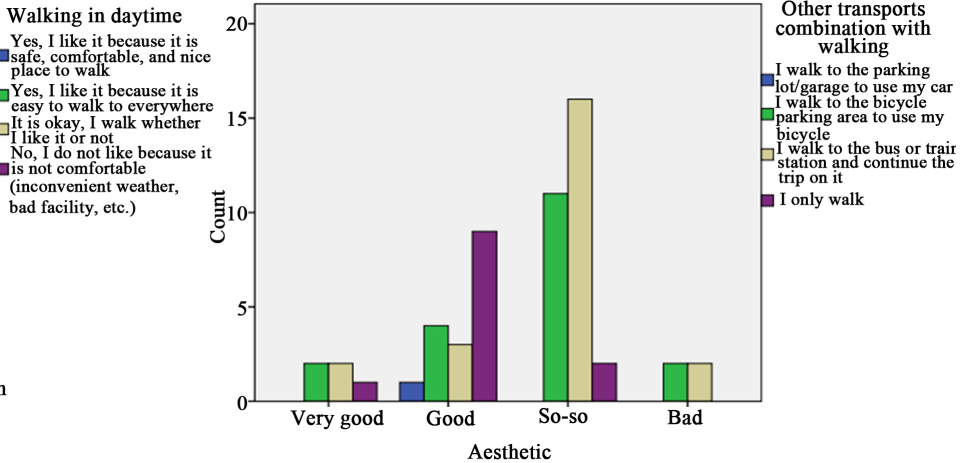

(b

Figure 31. Pedestrian crossing/bridge—-walking in daytime (a); aesthetic —other transp. combination with walking (b).

Table 6. Overall p-value scores of selected pairs of pedestrian environment—pedestrian activity.

\begin{tabular}{cccc}
\hline Pedestrian Profile & Pedestrian Activity & Pearson Chi-Square & Expected Count $<5$ \\
\hline Pedestrian crossing/bridge & Walking in daytime & 0.028 & $62.5 \%$ \\
Aesthetic & Other transports combination with walking & 0.032 & $68.8 \%$ \\
\hline
\end{tabular}

of Kitakyushu city. However authors identified that most of the students lived in the ward of Yahatanishi, which is in fact the neighboring ward and adjacent to the campus. Thus since most frequent walking location was around their houses, authors argued that the students profile represented partly of the people who experience walking in Yahatanishi. Please refer to Figure 32 for the location of walking area.

Going further in detail, authors could describe the profile by the stereotypes of single Japanese first year's students who live far away from their hometown, could not own or use car and motorcycle thus mainly depending on bicycle, walking, and public transports to go everywhere. Therefore they were physically quite active. The results of period of living in the current address also indicated that they were new inhabitants. Therefore authors would consider that they were supposedly still objective enough when giving responses about the pedestrian environment thus this should have been reflected toward the result of this experiment as well. Unfortunately this profile still possessed a relatively low level of acknowledgement toward current environmental issues. Therefore the value of low carbon urban mobility might have not been consciously reflected from their preferences.

Then in regard with the common activities, there were indications that they indeed walked in accordance with their daily activities which were ranging from day time to night time. This daily walking activities were in fact consisted of relatively short to medium distance trips with 5 minutes being the shortest one and 30 minutes being the longest one. Considering the average speed of Japanese of around 80 meters per minute, as mentioned in the early part of this paper, then the minimum common distance would be around 400 meters and the maximum common distance will be around 2400 meters or 2.4 kilometers. The purpose of the walking activities was also related to the profile of student which was going to the university. Another related behavior was that these walking activities were mostly taken also with the intention to reduce the travelling cost.

And also despite being in Japan as one of the safest country in the world (Institution for Economics and Peace, 2015), walking in the day time were still more preferable than in the night time because of the safety reason. Because safety was not just from crime but also from traffic since it was found that there were conflicts between pedestrian with car/motorbike and also with bicycle of which the later became the most reported. Therefore authors would argue that although the key-attribute of safety is a very important factor to encourage walking, it must be considered in regard to the local context of each place exclusively (Loukaitou-Sideris, 2006). This was also supported by the next finding which showed that when walking alone, the respondents relatively paid attention to the surrounding. This result resembled similar study which concluded that looking at the surrounding and using smartphone as the common activities when walking alone (Nuzir \& Dewancker, 2015). However authors noticed also from the result that the use of smartphone received higher attention of the pedestrian. This could be potential decisive factor in improving walking experience in the future. 


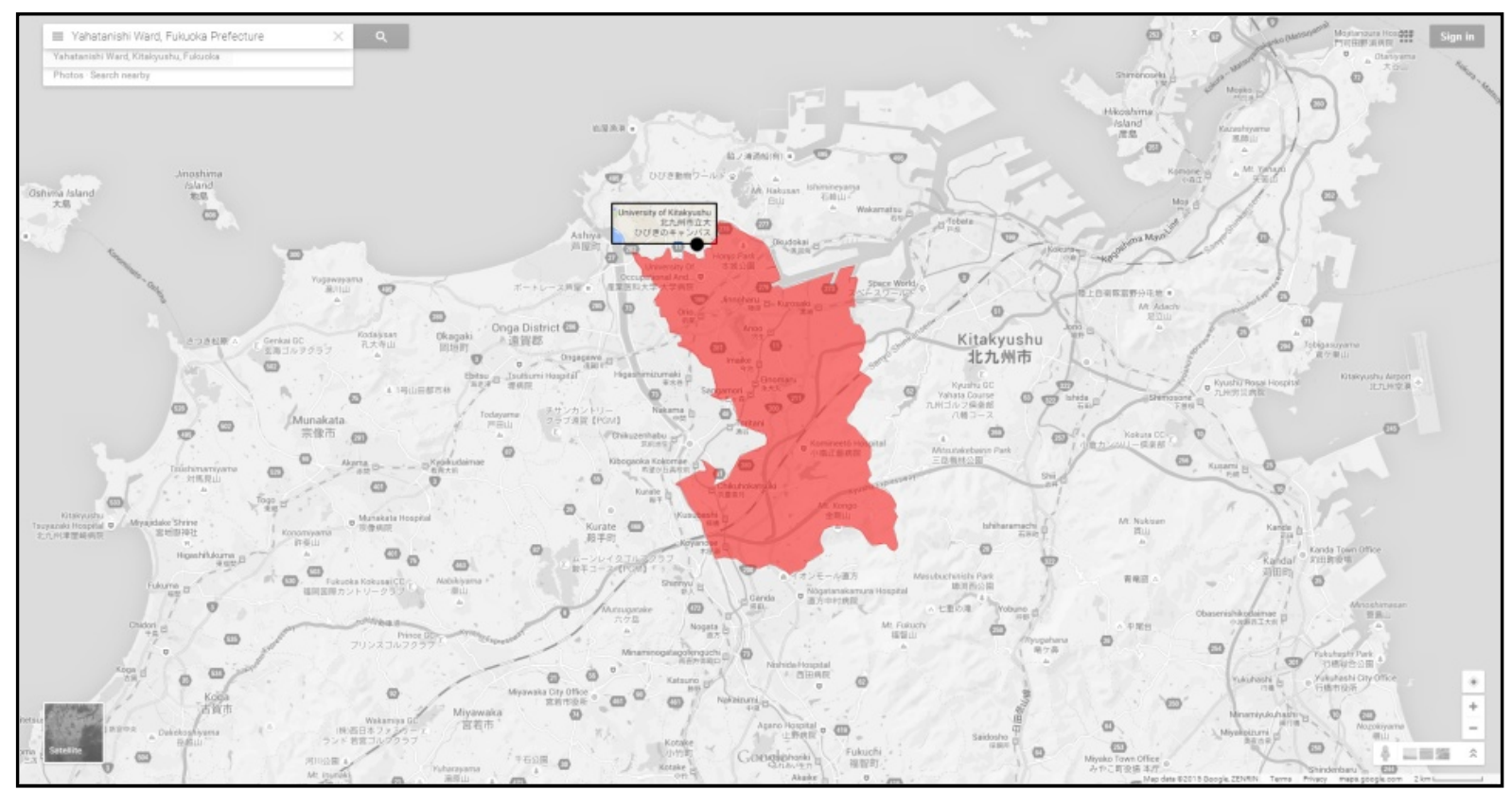

Figure 32. The Area of Yahatanishi Ward (colored in red) and the location of Hibikino campus of the University of Kitakyushu (black dot), within the context of Kitakyushu city. Source: Google Maps, 2015.

As for the key-attributes from the key-element of pedestrian environment, authors found that the respondents might have found difficulties in responding to several key-attributes using the scale measurement. This question was probably either difficult to understand. Or it was difficult for the students to determine the scale of the answers. These key-attributes were for example "land-use diversity", "distance to destinations", "population or neighborhood density", and so on. When facing this kind of difficulty, the students mostly just selected the "so-so" answer. In term of walkability, authors found indications that the pedestrian appreciated more the non-physical attributes such as the connectivity of the walking route and the weather condition rather than the physical attributes such as the public transport infrastructure and the universal design for disable.

Surprisingly authors found out that there wasn't any response of "very good" for the level of security. This result confirmed the similar finding from the key-element of pedestrian activity. Furthermore although the respondents confirmed the high level of service of the pedestrian crossing or bridge, it still could not manage to fulfill the expectation of the respondents for the safety of the traffic. Authors would argue that the level of expectation for safety inevitably related to the pedestrian profile and would be unique for each place as explained in the previous paragraph. Then the results again confirmed that the pedestrian facilities (physical factor) were generally in good condition especially the hard elements such as seating, street lighting, sidewalk, and so on. But this did not directly influence the environmental quality (non-physical factor), such as attractiveness, aesthetic, and cleanliness of the discussed pedestrian environment. However authors also found that the 14 out of 25 questions for this key-element of pedestrian environment were also mentioned by architect Jan Gehl as the main features for good walking conditions (Hass-Klau, 2015) which were as follow:

- A continuous and complete pedestrian network.

- A reliable feeling of safety that means protection from motorized traffic.

- Security through collective surveillance and activity, especially in darkness.

- Direct pedestrian routes with sufficient space—-wide sidewalks—and no obstacles.

- Stimulating and detailed facades, services and facilities facing the pedestrian streets.

- Comfort, such as low noise, good air quality, cleanliness and weather protection.

- Pedestrian facilities, like clean drinking fountains and toilets.

- Green spaces, flower beds, trees, etc.

- Seating: formal, informal, and commercial seating.

- Features that invite leisure activities and play.

- Art that generates identity with the town (and region). 
The next, authors would elaborate the association between the key-attributes from pedestrian profile and the key attributes from pedestrian environment. The students who currently live inside Kitakyushu mostly had already good appreciation toward the street lighting feature on their walking area. Similar results also showed that as for the key-attributes of "the level of security", "the width of sidewalk", "the walking comfort", "the cleanliness", and "the pavement", the students also appreciated the pedestrian environment inside Kitakyushu better compared to the same in the neighboring city of Kitakyushu. Therefore authors would argue that the strongest key-attributes of pedestrian environment in Kitakyushu city specifically Yahatanishi area were already identified by the respondents. Then in order to improve the walking condition in particular area, authors would suggest to pay more attention toward other key-attributes which were not yet appreciated by the respondents. Also from the next finding, author learned that the walking area in the vicinity of residential area dominated with detached houses were cleaner than the same near the apartments or mansions. However the walking comfort in the area of detached houses were more influenced by the weather condition in summer compared to the same in the area of apartments or mansions. This might be related to the distance to destinations which reflected also to the land-use diversity since detached houses mostly occupied larger plots of land compared to apartments or mansions.

By relating the key-attributes from pedestrian profile with the key-attributes from pedestrian activity, authors also learned different mobility choices of the pedestrian based on their living place, their walking destinations, and most importantly the level of services of the urban mobility methods. In this case study of Yahatanishi, Kitakyushu, in Japan, it was rather easy to conclude that one would prefer to walk for short to medium distance trips and to use public transportation for long distance trips. But this could not be the same scenario for other places which does not have a walkable pedestrian environment or does not have a reliable public transportation. For these places one would start to rely on private motorized vehicles. Lastly, as for the association of between the pedestrian environment and the pedestrian activity, authors would argue that the more intense of the activity that occurred in the walking area, the more influence of the environment toward the pedestrian. For example people who intensively walk in an area without combine it with other transport modes such as cycling or using public transports, would be the ones who mostly appreciate the aesthetic value of that particular walking area. However many associations of the key-attributes from both key-elements did not reflect a reliable result. Authors would argue that this was as a result of small number of responses.

In fact authors also found a phenomenon that might be related to cultural and psychological anomaly. It is understandable that almost none of either male or female students selected near side of the road for vehicles as their favorite walkway part since they might be afraid of the potential physical collision caused by the motorized vehicles. Yet interestingly there was no female students selected the middle part of pedestrian area as their favorite walkway part while on the other hand many male students selected this area as their favorite walkway part after the far side of the road for vehicles. This phenomenon could be a unique experience that needs to be dealt in order to improve the walking experience.

\section{Conclusion}

Various attributes addressing the issues on walking environment and walking condition possibly have distracted the efforts of creating better planning and development to promote walking to the citizen. It will take an enormous effort and time for them to consider all the attributes that are available. Therefore authors assess the possibilities of the utilization of the Pedestrian PL.AC.E. (Profile, Activity, and Environment) and its key-attributes using a survey questionnaire in order to confirm that it can serve as a framework for urban planning or assessment in promoting a walking-friendly environment. The framework should be able to identify the propensity of each key-attribute in order to understand the characteristic of research subject. This was the purpose of conducting descriptive analyses within each key-element.

By descriptive analysis, authors managed to conclude that as for the Pedestrian Profile, the responses represented the profile of fresh-men university students which are also new inhabitants to the area near to the university and physically active in general, thus naturally able not to rely on motorized transportation. Authors also identified that the students profile represented partly of the people who experience walking in Yahatanishi area. As for the Pedestrian Activity, author concluded that walking activity was conducted by the respondents in accordance with their daily activities in a form of short distance journeys. The walking activity was still influenced by concerns regarding safety from traffic (there were conflicts with cyclist) and crime especially 
during night time. Authors noticed also that the use of smartphone was intense thus it could be utilized to improve walking experience in the future. In regard to the Pedestrian Environment, there were positive evaluations of the physical condition of the pedestrian facilities. However in relation to the quality, the positive responses were decreased.

Then authors also argue that the framework also should be able to elaborate the relationship between the keyattributes within each key-element in order to find unique phenomena related to walking. This was investigated by conducting bivariate analysis. From pairing pedestrian profile and pedestrian environment, authors conclude that in order to improve the walking condition in Yahatanishi area, one could pay more attention toward keyattributes which were not yet appreciated by the respondents. By relating pedestrian profile with pedestrian activity, authors also learned different mobility choices of the pedestrian based on their living place, their walking destinations, and most importantly the level of services of the urban mobility methods. As for the association between pedestrian environment and pedestrian activity, authors conclude that the more intense of the activity in the walking area, the more influence of the environment toward the pedestrian.

The trial experiment for the questionnaire was necessary in order to understand the ability of the respondents to comprehend the questionnaire. Furthermore authors interpreted the outcomes in order to assess the feasibility of implementing the proposed concept of Pedestrian PL.AC.E. for understanding urban walking experience. Despite of the finding that several questions resulting homogeneous and bias responses, authors acknowledged important findings that reflect on the reality. Therefore authors were convinced that the framework could be further tested on more representative targets.

\section{Acknowledgements}

This study was supported by The University of Kitakyushu, Directorate General of Human Resource for Science, Technology, and Higher Education Republic of Indonesia, and Bandar Lampung University.

\section{References}

Blanco, H., Alberti, M., Forsyth, A., Krizek, K. J., Rodríguez, D. A., Talen, E., \& Ellis, C. (2009). Hot, Congested, Crowded and Diverse: Emerging Research Agendas in Planning. Progress in Planning, 71, 153-205. http://dx.doi.org/10.1016/j.progress.2009.03.001

Brown, B. B., Werner, C. M., Amburgey, J. W., \& Szalay, C. (2007). Walkable Route Perceptions and Physical Features: Converging Evidence for En Route Walking Experiences. Environment and Behavior, 39, 34-61.

http://dx.doi.org/10.1177/0013916506295569

Hass-Klau, C. (2015). The Pedestrian and the City. New York: Routledge.

Institution for Economics and Peace (2015). Global Peace Index 2015. New York.

Loukaitou-Sideris, A. (2006). Is It Safe to Walk? Neighborhood Safety and Security Considerations and Their Effects on Walking. Journal of Planning Literature, 20, 219-232. http://dx.doi.org/10.1177/0885412205282770

Manaugh, K., \& El-Geneidy, A. M. (2011). Validating Walkability Indices : How Do Different Households Respond to the Walkability of Their Neighbourhood? Transportation Research Part D: Transport and Environment, 16, 309-315. http://dx.doi.org/10.1016/j.trd.2011.01.009

Mateo-Babiano, I., \& Ieda, H. (2007). Street Space Sustainability in Asia: The Role of the Asian Pedestrian and Street Culture. Journal of the Eastern Asia Society for Transportation Studies, 7, 1915-1930.

Nuzir, F. A., \& Dewancker, B. J. (in press). Redefining PLACE for Walking: A Literature Review and Key-Elements Conception. Theoretical and Empirical Researches in Urban Management.

Nuzir, F. A., \& Dewancker, B. J. (2015). Understanding How to Improve Urban Walking Condition in Japanese Low Carbon Society. In Architectural Institute of Japan (Ed.), 54th Architectural Institute of Japan Kyushu Branch Research Meeting (pp. 457-460). Kumamoto: Architectural Institute of Japan.

Parks, J. R., \& Schofer, J. L. (2006). Characterizing Neighborhood Pedestrian Environments with Secondary Data. Transportation Research Part D: Transport and Environment, 11, 250-263. http://dx.doi.org/10.1016/j.trd.2006.04.003

Sauter, D., Hogertz, C., Tight, M., Thomas, R., \& Zaidel, D. (2010). Emotions of the Urban Pedestrian: Sensory Mapping. Pedestrians’ Quality Needs. Cheltenham: WALK21.

http://www.walkeurope.org/uploads/File/publications/PQN\%20Final\%20Report\%20part\%20B4.pdf

Tsukaguchi, H. (2010). Comparative Study of Pedestrian Travel Culture in Different Cities in Japan. Journal of the Eastern Asia Society for Transportation Studies, 8, 1164-1178. 